IRA-International Journal of Applied Sciences ISSN 2455-4499; Vol.11, Issue 03 (June 2018)

Pg. no. 37-45.

Institute of Research Advances

https://research-advances.org/index.php/IRAJAS

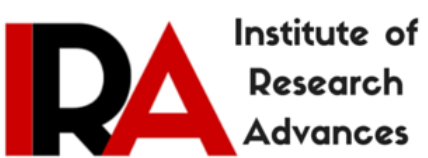

\title{
Monitoring, Predicting and Quantifying Soil Alkalinity, Sodicity and Salinity in Blue Nile State, Sudan, Using Soil Techniques, Remote Sensing and GIS Analysis; Case Study: Blue Nile River
}

\author{
Elhag A.M.H. ${ }^{1 \#}$, Gumaa Y.S.A. ${ }^{2}$ and Osman E.H. ${ }^{3}$ \\ and Scientific Research, Khartoum North ( Al- Kadaro) Sudan. \\ Research, Khartoum North ( Al- Kadaro) Sudan.. \\ \# corresponding author. \\ Type of Review: Peer Reviewed. \\ DOI: http://dx.doi.org/10.21013/jas.v11.n3.p2
}

${ }^{1}$ University of Bahri, Faculty of Natural Resources, Basic Science Department, Ministry of Higher Education

${ }^{2}$ Ministry of Agriculture \& Forestry, General Forestry Administration, Blue Nile State, Sudan.

${ }^{3}$ University of Bahri, Faculty of Natural Resources, Forest Department, Ministry of Higher Education and Scientific

\section{How to cite this paper:}

Elhag A.M.H., Gumaa Y.S.A., Osman E.H. (2018). Monitoring, Predicting and Quantifying Soil Alkalinity, Sodicity and Salinity in Blue Nile State, Sudan, Using Soil Techniques, Remote Sensing and GIS Analysis; Case Study: Blue Nile River. IRA International Journal of Applied Sciences (ISSN 2455-4499), 11(3), 37-45. doi:http://dx.doi.org/10.21013/jas.v11.n3.p2

(C) Institute of Research Advances.

(cc) BY-Ne

This work is licensed under a Creative Commons Attribution-Non Commercial 4.0 International License subject to proper citation to the publication source of the work.

Disclaimer: The scholarly papers as reviewed and published by the Institute of Research Advances (IRA) are the views and opinions of their respective authors and are not the views or opinions of the IRA. The IRA disclaims of any harm or loss caused due to the published content to any party.

Institute of Research Advances is an institutional publisher member of Publishers International Linking Association Inc. (PILA-CrossRef), USA. The institute is an institutional signatory to the Budapest Open Access Initiative, Hungary advocating the open access of scientific and scholarly knowledge. The Institute is a registered content provider under Open Access Initiative Protocol for Metadata Harvesting (OAI-PMH).

The journal is indexed \& included in CAS Source Index of Chemical Abstracts Service of American Chemical Society (USA), Index Copernicus (IC Value 85.27), WorldCat Discovery Service (USA), CrossRef Metadata Search (USA), WorldCat (USA), OCLC (USA), Open J-Gate (India), EZB (Germany) Scilit (Switzerland), Airiti (China), Bielefeld Academic Search Engine (BASE) of Bielefeld University, Germany, PKP Index of Simon Fraser University, Canada. 


\begin{abstract}
This study focused on the assessment of land degradation on a transect of $20 \mathrm{~km}$ along the Blue Nile River (10 $\mathrm{km}$ at each side of the river) within the Blue Nile state, Blue Nile State, Sudan. Through mapping and monitoring the changes that occurred in the soil properties, due to Water Erosion, Vegetations degradation, mismanagement in addition to the Human activities and Climatic change The study attempted also to update some information in the study area such as chemical properties using different methods of data transformation and analysis such as: Soil analysis technique, GIS and remote sensing analysis. The research was based on the data and information deduced and extracted from soil survey data, soil analysis, and remote sensed data, in addition to fieldwork verification and other sources. The study covered an area about $346483.43 \mathrm{ha}$. Soil analysis and data compilation from other sources showed that the soil of the study area witnessed remarkable changes during the study Period (1990 - 2015). The degradations affected the Soil and Vegetations covers of the study area in both side around the Blue Nile River. The analysis indicated that soil degradation was taken place in the study area specially the top west and south east parts of the area which was affected by some buckets of salinity, northern part shown moderate level of acidity while the Part from the south East and South west area shown moderate level of Alkalinity. Assessment and evaluation of the soil of the study area in respect to soil texture revealed that $15 \%$ of the total area received some Sand deposits in the study area which it considered the beginning or indicator of soil degradation in the south west and northern part of the study area, while the SAR analysis indicated that all the soils of the study area fell within none sodic class. According to framework of the land suitability $(F A O, 1976)$ revealed that the soil of the study area is moderately suitable (S2) for agriculture.
\end{abstract}

Keywords: Soil Sciences, GIS Mapping, Blue Nile River

\title{
INTRODUCTION:
}

Monitoring soil degradation is not only necessary to determine changes related to the real extent of erosion areas or mismanagements but also it enables the evaluation of programmes of soil conservation programme executed in that area. Salinity and sodicity are separate and unique descriptions of the impact of soluble salts in soil and water. Sodicity represents the relative predominance of exchangeable sodium compared to other exchangeable cations, chiefly calcium, magnesium, potassium, hydrogen and aluminium expressed as ESP (exchangeable sodium percentage).

The sodium adsorption ratio (SAR), is another expression of sodicity that refers to the ratio of adsorbed sodium and the sum of calcium and magnesium. Soil salinity is a characteristic of soils relating to their content of water-soluble salts and expressed mostly as ECe (electrical conductivity of paste extract) and is measured as dS m-1 (Charman and Murphy, 2000). The inter-relation of all these soil parameters is important for the interpretation of their measures (van de Graaff and Patterson, 2001).

The soils of desert and semi desert regions of Sudan, particularly the high terrace of river Nile and its tributaries are affected by salt. They are characterized by relatively low nutrient content; ranging between $0.01-0.02 \%$.

The salinity and waterborne salts accumulated during the repeated cycles of water use have negative impacts on no saline soils which could cause soil degradation by secondary Stalinization (Abdalla 1986; Mustafa 1986). These problems become more critical as increasing population leads to more intensive use of land and water, bringing the unused or the marginally used land resources into service.

In such reigns, to increase the yield, entire physical and biological systems involved in saline agricultural land must be fully understood and carefully environmental managed without exacerbating the existing problems is needed.

According to Eswaran, H. (1998) and Eswaran and Kapur (1998) before monitoring, we should determine what to monitor and what should be the time interval for that monitoring, because different processes of degradation require different time intervals to be recognized. They also stated that salinization monitoring should be probably, done every year, sheet erosion-monitoring could be done every five years while gully erosion monitoring may require more than five years.

\section{STUDY AREA:}

The study area is carried out on a transect of $20 \mathrm{~km}$ along the Blue Nile River (10 km at each side of the river) within the Blue Nile state, that represents the direct and effective watershed area of the Blue Nile River in Sudan. The study covered an area about 346483.43 ha, (Fig 1). 


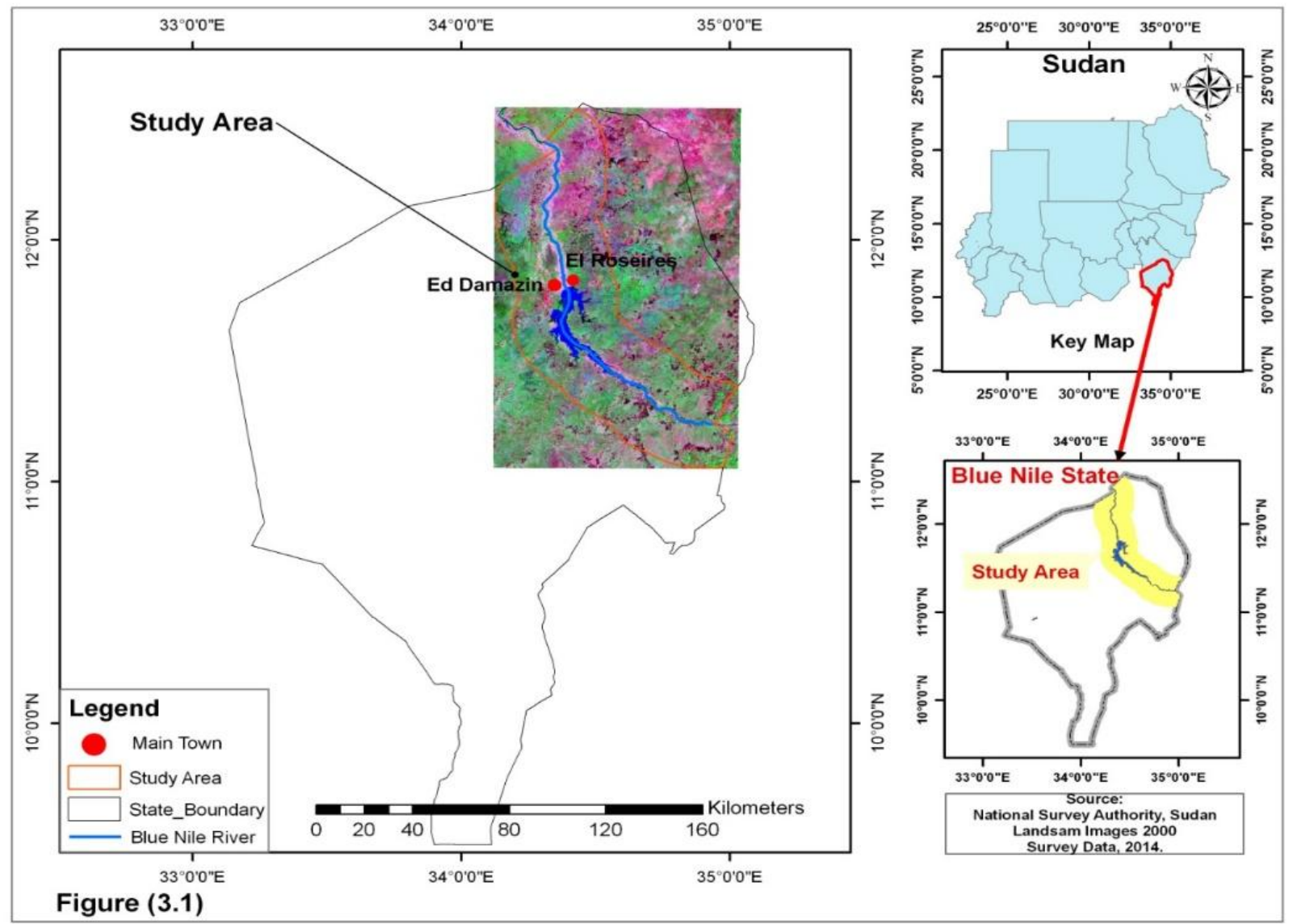

Figure 1: Location map of the study area

Populations are mainly farmers live around the study area. The soil of the study area is black cotton soil (Vertisols) and recent deposition soils (Entisols), and some Soil shown moderate level of Alkalinity and Acidity.

The climate is typical of the high rainfall Woodland Savannah. The average rainfall between $750-1200$, it start at May reaches peak at August and ends in October. The relative annual humidity is between $60-65 \%$ and the average annual temperature range between 35-40o C. (Meteorology Office, Damazin, 2017).

The Blue Nile is supports a rich diversity of flora and fauna. Over 50 species of birds have been identified in the Nile including migratory species. The system is surrounded by Acacia woodland especially Acacia nilotica around the Nile and the Rosaries Dam and many broad leaves tree species in the south area of the Nile at the Ethiopian border, in addition to many fish and wildlife species.

\section{METHODOLOGY:}

Four sub images (1990, 2000, 2010 and 2015) from land-sat (TM and ETM) and Digital Elevation Models covering the study area were used. Fieldwork was conducted within the period 1st December 2015 to 5th Marsh, 2016 in a total area of approximately 346483.43 ha, which represents the study area. GPS (Garmin 62C) was used to navigate among check samples and to record the coordinates (X, Y and Z values) of all each check sample. Soil samples were collected from different selected locations to cover the variability that observed from satellite image analysis.

Different soil samples strategies were applied depending on satellite image interpretation and morphological and differences physical properties (colour, texture, structure...etc.). Soil samples were collected from one depth (0-30 $\mathrm{cm}$ ) with a total number of 783, the distance between adjacent soil samples (in all directions) was $2 \mathrm{~km}$ (Fig 2). The soil samples were analyzed using the facilities of the department Basic Science (University of Bahri, College of Natural Resources and Environmental Studies) and department soil and environment science (Faculty of Agriculture, U of K.) The flowing properties were determined in soil samples:

- Soil Reaction: Soil pH was measured in soil paste using analogue $\mathrm{pH}$-meter JENWAY. 
- The Electrical Conductivity (ECe): The electrical conductivity of the saturation extract (ECe) was measured by conductivity meter WAPcm 35 (model $\mathrm{cm} 35$ ).

- Soluble Calcium and magnesium: Calcium and magnesium were determined volumetrically with titration against ethylene diamine tetra acetate (E.D.T.A).

- Sodium: Sodium was determined photometrically using Corning EEL flame photometer.

- Sodium Absorption Ratio: (Sodium absorption ratio was estimated from values of calcium, magnesium and sodium of saturated past extract. Exchangeable sodium percentage (ESP) was from regression equation of ESP on SAR) (Klute, 1965).

- Soil Texture (Hydrometer Method).

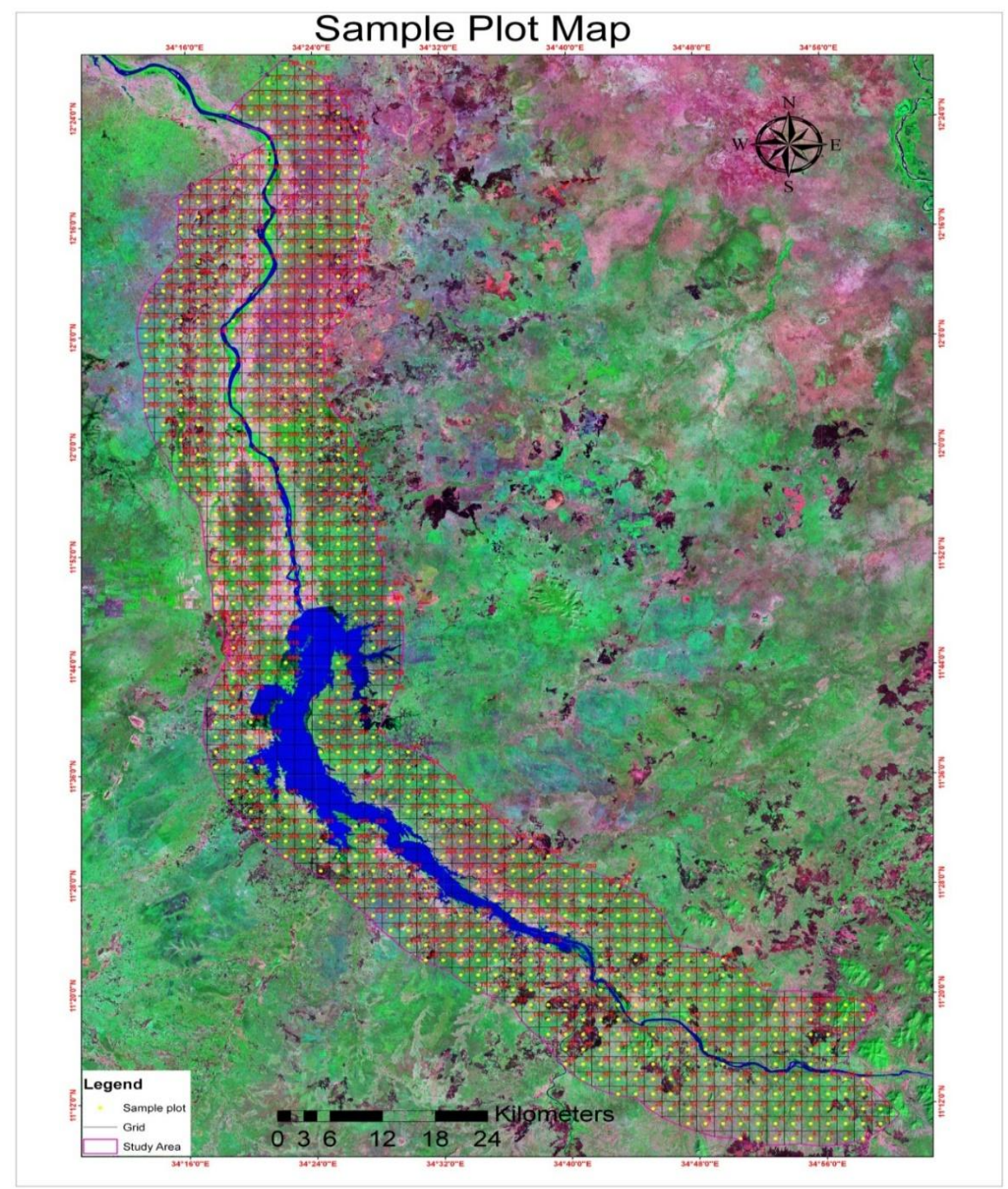

Figure 2: Location of auger and observation sites

\section{RESULTS AND DISCUSSION:}

The soil analysis indicated that most of the soils of the study area are non-saline and non-Alkaline, non - acidity soil except some buckets at surface and subsurface samples at the top east south east and south west parts of the study area which was saline, alkaline and acidity soil.

The assessment and evaluation of the soil of the study area in respect to electrical conductivity (E.Ce) revealed that 95.5\% of the total area fell within the first level of classification (Non-Saline Soil), which is suitable for crop cultivation, and this agreed with Eltom $(1973,1987)$ and Eltom (2004). 


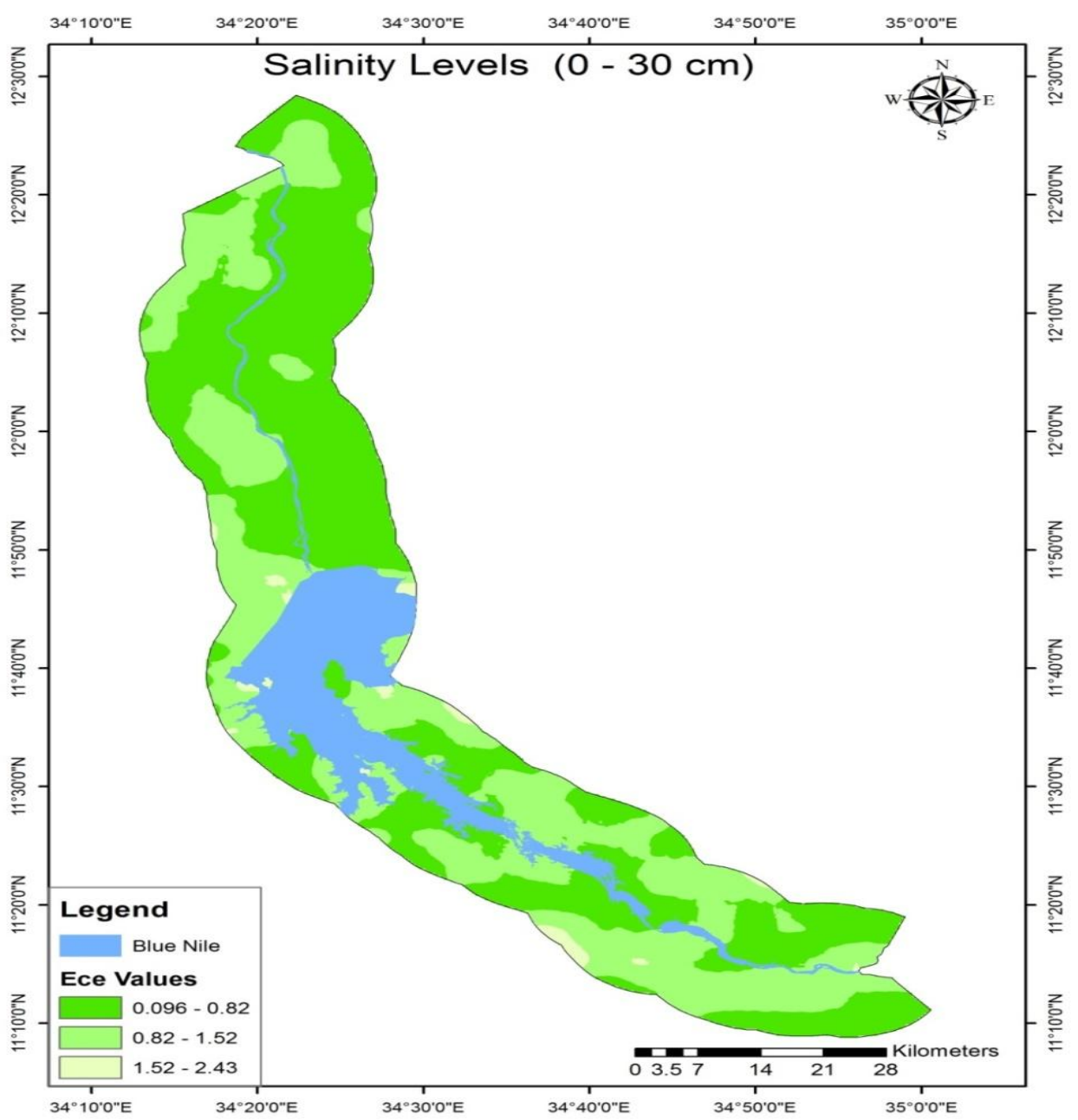

Figure (3) Salinity levels $(0-30 \mathrm{~cm})$.

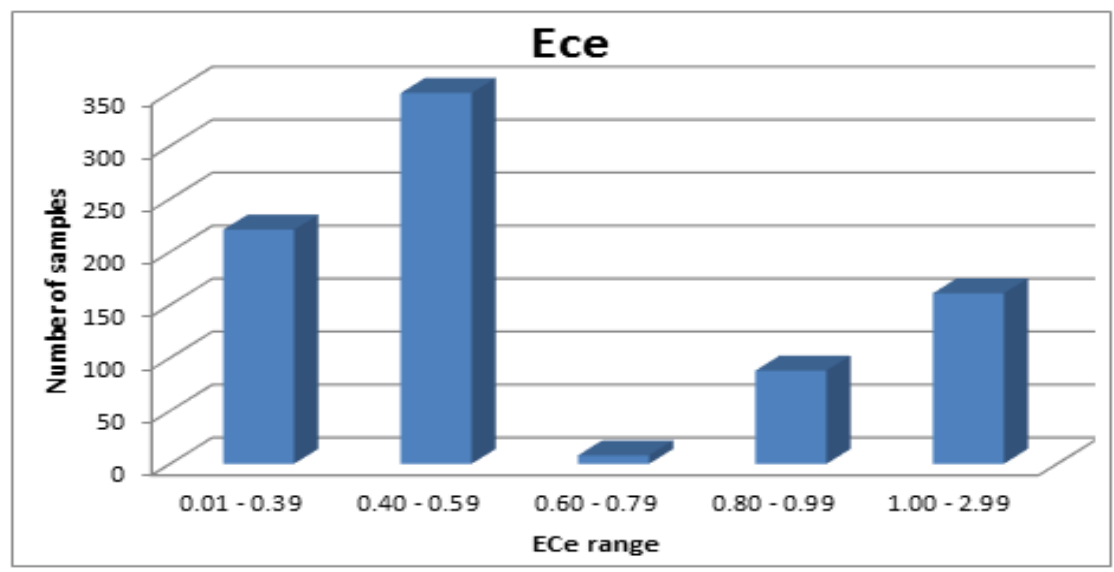

Figure (4) Salinity levels (ECe) base number of sample

Figure (3 and 4) shows the different ECe values of the examined soil sample the study area. In general the result indicated the ECe is ranging between 0.01 to $2.99 \mathrm{ds} / \mathrm{m}$. About $50 \%$ of samples have ECe ranging between 0.4 to 0.5 (Table 1). 
Table (1) ECe range

\begin{tabular}{|c|c|}
\hline ECe range & No of Sample \\
\hline $0.01------0.39$ & 221 \\
\hline $0.40------0.59$ & 350 \\
\hline $0.60------0.79$ & 8 \\
\hline $0.80-----0.99$ & 88 \\
\hline $1.00------2.99$ & 161 \\
\hline
\end{tabular}

Soil samples analysis revealed that the soil reaction $(\mathrm{pH})$ is ranging from neutral to moderate alkaline which is not unexpected for soils of savannah and semi savannah region (Fig 5, 6 and Table 2).

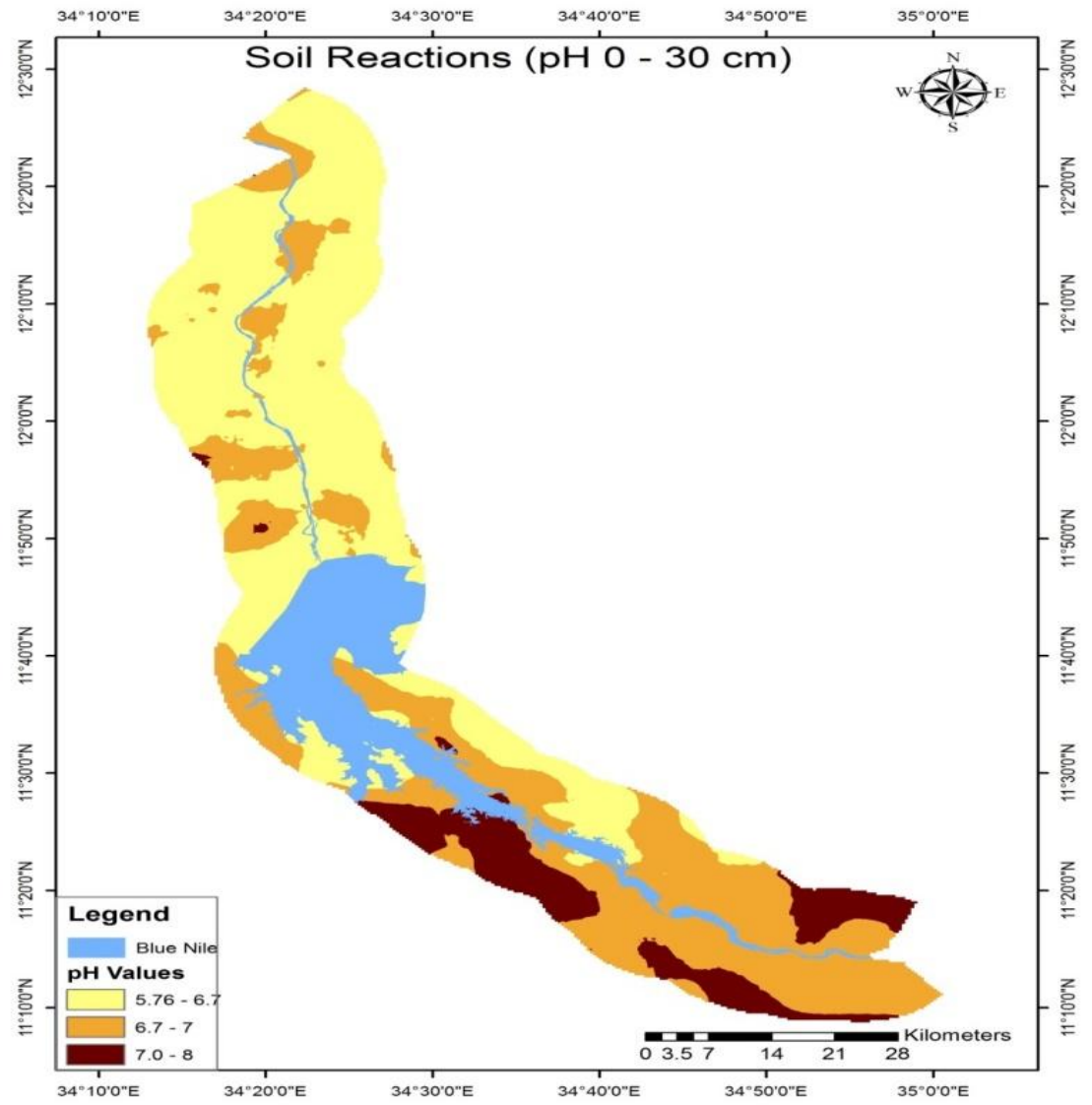

Figure (5) Soil Reaction (pH 0-30cm)

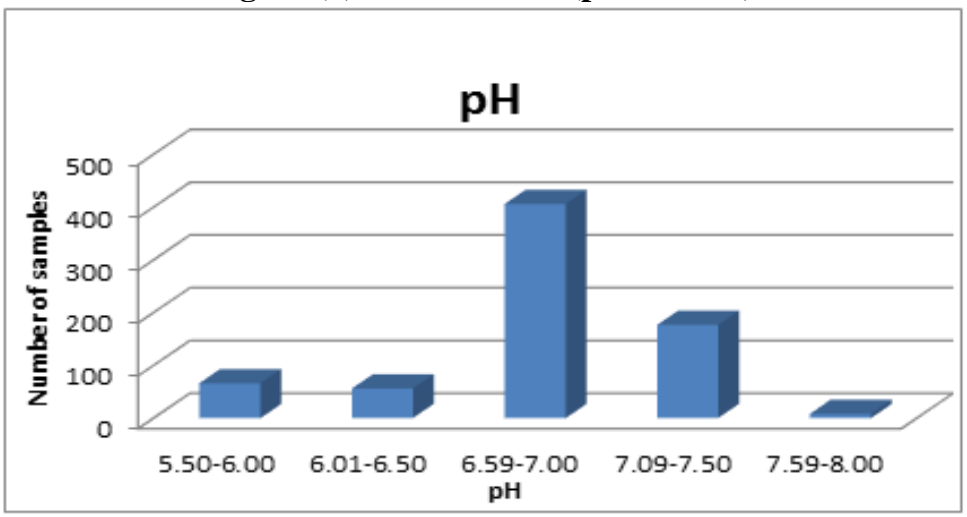

Figure (6). pH range and number of sample 
Spatial $\mathrm{pH}$ maps for the study area were divided into three classes, as shown in figure (5) the neutral and moderate alkaline class ( $\mathrm{pH}=6.7$ to 7 and 7 to 8 ), moderate Acidity class ( $\mathrm{pH}=5.76$ to 6.7 )

The measured soil $\mathrm{pH}$ values are ranging between (5.00 - 8.00) shown in table (2). About $58 \%$ of samples have $\mathrm{pH}$ ranging between 6.59---7.00 (Table 2).

\section{Table (2) Soil Reaction (pH) base number of sample}

\begin{tabular}{|c|c|}
\hline $\mathrm{pH}$ & No of sample \\
\hline $5.50---6.00$ & 66 \\
\hline $6.01---6.50$ & 56 \\
\hline $6.59---7.00$ & 406 \\
\hline $7.09---7.50$ & 177 \\
\hline $7.59---8.00$ & 8 \\
\hline
\end{tabular}

(Fig 7) The assessment and evaluation of the soil of the study area in respect to soil texture revealed that $15 \%$ of the total area received some Sand deposits in the study area which it considered the beginning or indicator of soil degradation in the south west and northern part of the study area, while $85.5 \%$ of the total area fell within the first level of classification (mainly loam, sand clay loam) which is suitable or good for the crops.

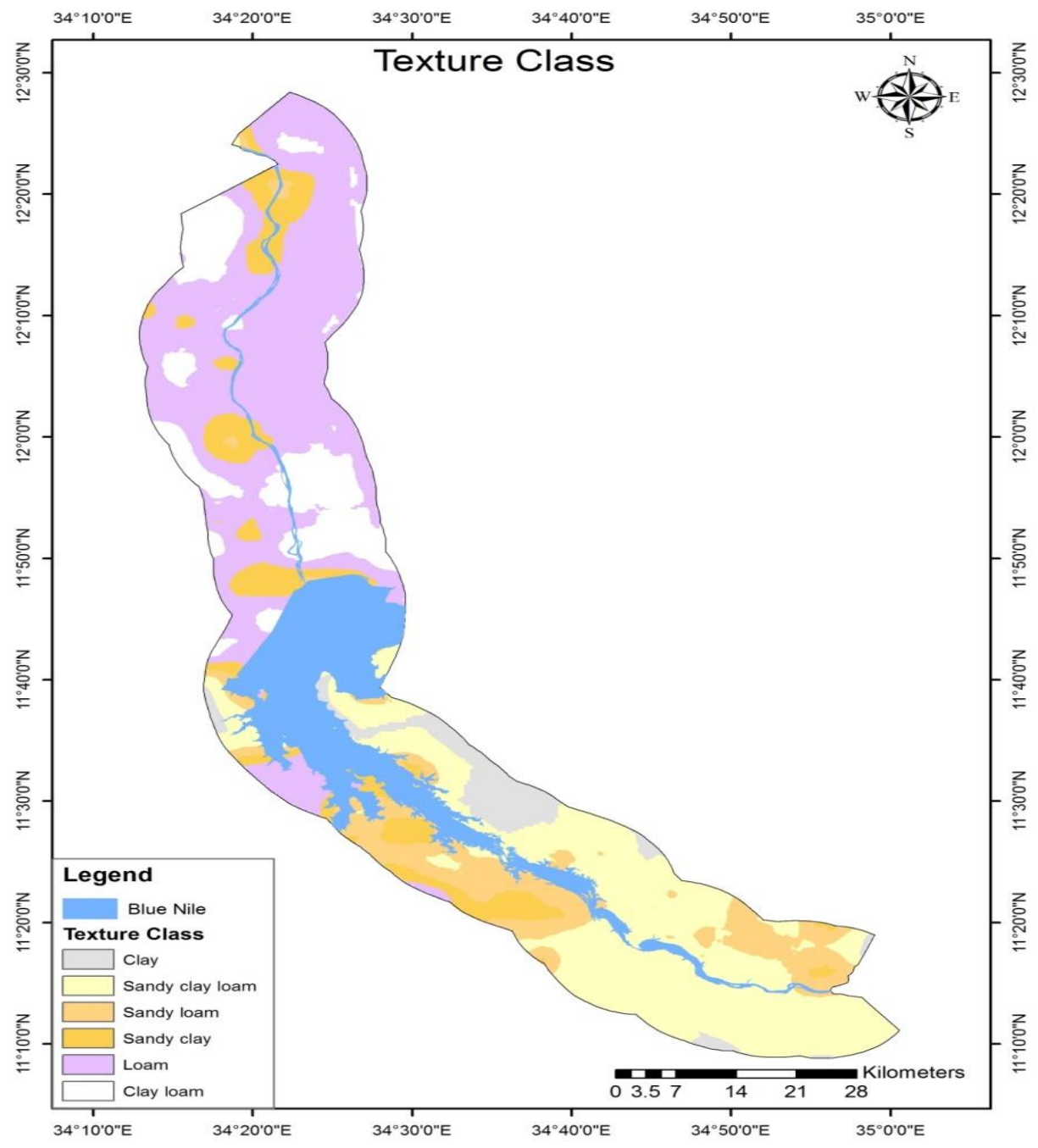

Figure (7) Soil Texture class 
The spatial variability of sodium adsorption ratio in study area indicated that soil is non-sodic (SAR less than13). Hence for convenience, soils were divided into three classes, as shown in figures (8), a similar result was found by UNDP (1970).

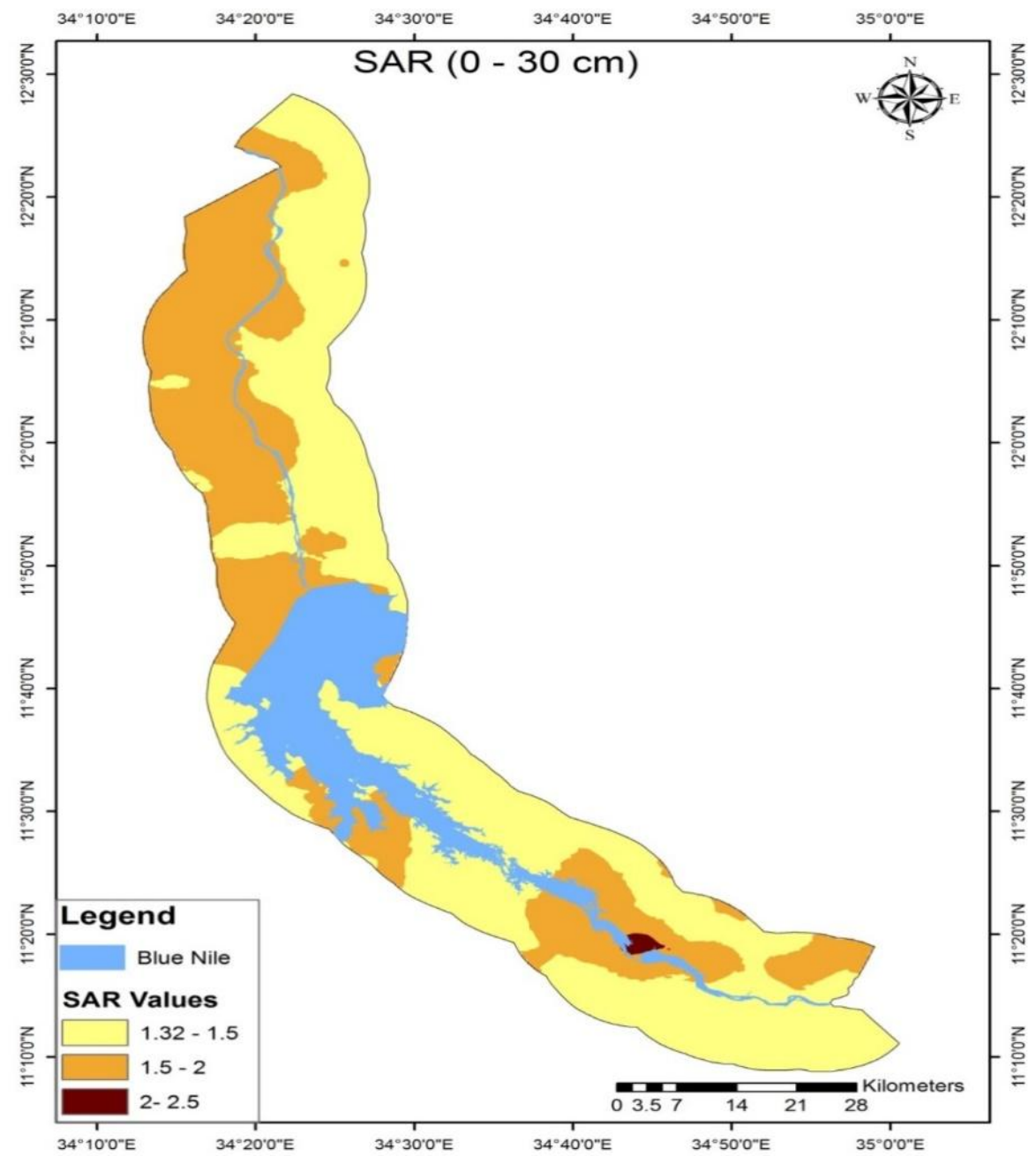

Figure (8) SAR Values in the study area.

Field work and survey results revealed land degradation signs which might be due to bad management such as mismanagement and over grazing.

\section{CONCLUSION AND RECOMMENDATION:}

The study revealed different signs of land degradation in the study area as judged by change in soil chemical properties. These changes indicated decrease in cropped yield and productivity, decrease in vegetation cover, expansion saline, Acidity and alkaline soils around and inside the study area as increased of buckets of saline, alkaline and deposits of sand. These signs could be revised with the use of agricultural indicators. Land degradation as reduction in biological productivity can be interpreted from crop yields.

Soil analysis showed that chemical properties of the soil had revealed different changes; some parts were affected by slightly salinity and modally alkaline that had negative impact on the soil productivity. The observed land degradation (poor natural vegetation and poor soil fertility) was due to both climate changes and human activities. Based on these finding the following recommendation can be stated:

1. Conduction of periodical assessment and monitoring of natural resources with use of remote sensing methods. 
2. Remote sensing and GIS should be used to map the chemical, physical land degradation.

3. Giving more attention to the extension aspects to increase the awareness of the local community to the importance of Soil and land degradations.

4. Adoption of governmental agricultural policy based on the above recommended method of periodical and up-to-date natural resource assessment which can conserve the natural resources.

5. The reclamation of the slightly saline and/or alkaline of the soils which found in some parts of the study area should be attempted.

6. Periodic monitoring of severity and extent of land degradation is needed.

7. New policies and practices of agricultural extension should be adapted to alert farmers to the threats of land degradation and sand creeping in particular.

8. Some measures are needed to retard land degradation in the study area.

9. Encouragement of people to adopt practices of sustainable natural resource management.

\section{References:}

[1]. Abdalla, H.H. (1986). Extent and management of problem soils in Sudan saline sodic soil, World Soil Resources Re.l'earch 58, 90-109.

[2]. Charman, P. E. V. and Murphy, B. W., (Eds.) 2000. Soils: Their Properties and Management; Oxford University Press, South Melbourne.

[3]. El Tom, O.A 2004. Manual for land suitability classification for agriculture with particular reference to Sudan. Soil Survey Administration, Ministry of science and technology.

[4]. El Tom, O.A.1973. "Semi-Detailed Survey of South Khartoum Area and Blue Nile" Soil Survey Dept., Wad Medani, Sudan.

[5]. El Tom, Osman A. (1987) General properties and management of Vertisols in Sudan. Soil Survey Administration Technical Bulletin, Wad Medani, Sudan.

[6]. Eswaran, H. 1998. Impact of land degradation in the Mediterranean region. Bulgarian J. of Agrc.Sci.

[7]. Eswaran, H. and Kapur, S. (1998) Land degradation newsletter of the international task force on land degradation, Vol. 2001.

[8]. KLUTE (A.), 1965, Laboratory Measurement. Methods of Soil Analyses (ed. C.A. Black). Madison

[9]. Meteorology Office-Damazin, 2017.

[10]. Mustafa, M.A. (1986). Salt affected soils in the Sudan: their distribution, properties and management. Reclamation and Revegetation Research 5, 115-12.

[11]. UNDP (1970), Strengthening of the soil survey divisic of the ministry of agriculture, the Sudan, semi detailed soil survey of part of the central clay plain, technical report 3.

[12]. Van de Graaff, R. and Patterson, R. A.; 2001. Explaining the Mysteries of Salinity, Sodicity SAR, and ESP in On-site Practice; in: Proceedings of On-site '01 Conference: Advancing On-site Wastewater Systems, edited by Patterson, R. A. and Jones, M. J.; Lanfax Laboratories, Armidale, Australia. 